\title{
Representação política em Cuba: um Estado dos trabalhadores?
}

\author{
Tádzio Peters Coelho*
}

\begin{abstract}
Resumo
A Revolução Cubana empreendeu construir um Estado nacional-popular, que combina uma adesão social antiimperialista, antimonopolista e antilatifundista que faz oposição contra a classe dominante externa. Por isso, não descarta o controle estatal por parte da burguesia nacional, e mesmo que não seja liderado pelas classes populares, envolve a participação popular. Trata-se de um nacionalismo dos dominados que guarda, assim, um caráter progressista. Na representação política dos trabalhadores cubanos existem alguns aspectos que podemos chamar de socialistas. Os trabalhadores interferem em parte dos processos de decisão política, exatamente por se tratar de um "Estado nacional-popular", atendendo algumas das demandas do setor nacional e do proletariado em geral.

Palavras-chave: Revolução Cubana; Estado Nacional-Popular; Representação Política.
\end{abstract}

\section{Introdução}

A revolução cubana foi um dos privilegiados momentos históricos em que se praticou a autonomia popular, onde houve a tentativa da ascendência a uma sociedade socialista. Mas após o fim do "socialismo" no Leste europeu, este tema foi deixado de lado. Apesar de muito discutidos, os problemas contemporâneos e o futuro do socialismo em Cuba são pouco estudados na atualidade. Alguns entendem que Cuba pode ser o único reduto remanescente do socialismo derrubando, assim, a tese do fim da história defendida por Francis Fukuyama (1992) segundo a qual o socialismo se esgotou, prevalecendo o modo de produção capitalista. Para outros estudiosos, Cuba pode ter posto em evidência outra forma de regime político, que objetiva a transição para o socialismo. Mas o Estado é aparelho de repressão, e atua a favor das classes dominantes, por isso está assentado sobre a configuração das classes sociais.

$\mathrm{Na}$ contramão da teoria do crescimento, de acordo com a qual a justiça social só é possível através do crescimento econômico do país, Cuba prova que é possível

\footnotetext{
* Mestrando em Ciências Sociais pela UERJ (Universidade do Estado do Rio de Janeiro) e graduado em Ciências Sociais pela UEL (Universidade Estadual de Londrina). Email: tadzioguaiabera@gmail.com.
} 
atender algumas das necessidades básicas das classes baixas, mesmo com sua pequena economia antilhana.

Pretendemos com esse trabalho aprofundar a discussão sobre o Estado cubano e sua relação com as classes trabalhadoras, sendo esse o único Estado que se propõe, em sua Constituição, o socialismo - de caráter irrevogável - dentro do continente latino-americano:

\footnotetext{
Artículo 1o.- Cuba es un Estado socialista de trabajadores, independiente y soberano, organizado con todos y para el bien de todos, como República unitaria y democrática, para el disfrute de la libertad política, la justicia social, el bienestar individual y colectivo y la solidaridad humana (Constitución de la Republica de Cuba, 1992).
}

Partimos da hipótese que este supos to socialismo de Cuba adquiriu uma forma ideológica, através da qual se legitima a dominação sobre os trabalhadores com o discurso ideológico de que se trata de um Estado dos e para os trabalhadores, que representa os seus interesses, e dessa forma, não se extinguiu o modo de produção capitalista. Por isso, trata-se de um capitalismo de Estado, em que os meios de produção e o Estado são controlados por uma minoria ao mesmo tempo em que, em sua representação política, comporta vários elementos do socialismo, pois os trabalhadores têm meios políticos efetivos de fazer valer suas decisões.

Por isso tal configuração, além de heterogênea, é totalmente específica dentro do cenário continental. Analisando a representação política dos trabalhadores cubanos, tentamos desvendar em que medida são implementadas suas demandas e de que forma seus respectivos representantes intervêm a favor de seus interesses políticos. Ainda procuramos descobrir quais contradições guardam esses processos políticos, e qual o espaço de reivindicação que, efetivamente, o proletariado tem nesse aspecto. Quem decide os rumos a serem tomados? Os deputados e delegados ou a população? Como funciona a relação entre trabalhadores e Estado revolucionário no que se refere aos processos de decisão? De que forma os trabalhadores intervêm nesse processo? Intentamos com este trabalho contribuir para a discussão de um caminho específico tomado pela Revolução Cubana, que perpassa o nacionalismo: "A Revolução Cubana tem, portanto, de ser compreendida como uma via específica de 
solução aos problemas de miséria e ditadura produzidas pelo subdesenvolvimento na região do Caribe latino-americano (Sader, 2001, p. 91)".

Em relação ao Estado revolucionário, partimos da hipótese de que 0 burocratismo não foi liquidado e não houve uma efetiva instauração do controle proletário sobre o corpo burocrático estatal (Saes, 1998, p. 20), mesmo que várias das necessidades do proletariado tenham sido atendidas - guardando assim um caráter progressista em relação à representação política na democracia liberal. Essas são características próprias do Estado nacional-popular, que comporta um caráter de classe heterogêneo, suportando em seus limites tanto a participação popular quanto a participação burguesa.

Na representação política dos trabalhadores cubanos existem alguns aspectos que podemos chamar de socialistas por atender a várias demandas do proletariado. Prova disso é o relatório do Banco Mundial (2010) no qual a taxa de mortalidade de Cuba é de 5,9/1000. No Brasil essa taxa é de 19,4/1000 e nos EUA de 7,5/1000. Sua expectativa de vida atinge 78,77 anos, enquanto nos EUA é de 78,09 anos e no Brasil de 72,76 anos.

\section{A representação política}

A revolução empreendeu construir, portanto, um Estado nacional-popular, que combina uma adesão social antiimperialista, antimonopolista e antilatifundista que faz oposição contra a classe dominante externa. Por isso, não descarta o controle estatal por parte da burguesia nacional, e mesmo que não seja liderado pelas classes populares, envolve a participação popular, além de atender várias de suas reivindicações. Trata-se de um nacionalismo dos dominados que guarda, assim, um caráter progressista. Mas a revolução não foi simplesmente um movimento realizado por um grupo de guerrilheiros, envolveu, também, num amplo contexto social, as classes proletárias.

Mesmo que residam na revolução fortes vínculos com o povo e trabalhadores em geral, são várias as limitações desse processo ante os interesses do proletariado. 0 primeiro a citarmos, e principal limitação, é o processo revolucionário ter sido liderado 
por uma pequena burguesia essencialmente nacionalista, mesmo que aliada às classes trabalhadoras. Essa limitação é a causa da formação de uma "vanguarda" composta por, principalmente, ex-líderes estudantis. A vinculação orgânica do proletariado se deu de maneira apenas parcial. A pequena burguesia cubana, aguçada pelo forte sentimento nacionalista e anti-neocolonialista, entra em choque com uma classe dominante que é predominantemente externa, aliando-se nesse processo a um proletariado que vinha com um forte histórico de ascensão na luta reivindicatória.

Harnecker chama a representação política em Cuba de "processo de participação institucionalizada das massas na gestão do Estado" (1974, p. 35). Na representação política dos trabalhadores em Cuba configuram alguns aspectos positivos, principalmente se comparados aos do sistema político de representação de outros países latino-americanos. Podemos enumerar três aspectos relevantes na representação política cubana: 1) O caráter revogável do mandato dos deputados e delegados. O colégio eleitoral que sufragou o deputado pode revogar seu mandato caso esteja insatisfeito com a sua atuação; assim os que o elegeram também podem retirá-lo de seu cargo mantendo o eleito sempre ligado aos interesses da população. Isso também pode ser feito por meio da Assembleia Popular. 2) Os delegados eleitos devem prestar contas à população de sua circunscrição duas vezes ao ano, inteirandoa em relação aos processos políticos de suas demandas, e identificando essas demandas para levá-las de volta às assembleias, municipal, provincial ou nacional. 3) As eleições em nível local nas quais quem postula de forma direta os candidatos e as políticas a serem implementadas são os trabalhadores.

Mas é no âmbito municipal que a representação política em Cuba traz elementos importantes no que diz respeito à participação popular. Apesar de crítico ferrenho do regime cubano, Bandeira (2002, p. 40) reconhece que existem alguns aspectos positivos na estrutura de representação política cubana, como a possibilida de do colégio eleitoral, que sufraga o candidato, poder revogar o mandato dos delegados e deputados, mecanismo inspirado na Comuna de Paris de 1871. As eleições no nível municipal são realizadas a cada dois anos e meio, o que, teoricamente, permite maior renovação e aumento da fiscalização. 
Cuba herdou uma série de características da URSS. As semelhanças eram um regime de economia centralizada, com peso decisivo do Estado, e um regime político que praticamente se confunde com o Estado. Mas são as diferenças que explicam os destinos separados dos dois países. Cuba, ao contrário da URSS, "preferiu manter os subsídios aos produtos básicos, aumentando a carga econômica do Estado, sem penalizar socialmente os setores mais necessitados. O que não quer dizer que a legitimidade não tenha sido abalada" (Sader, 2002, p. 110).

Uma das consequências do excesso de centralização é identificada por Fernandes (2007, p. 319): há uma "baixa densidade da socialização política propriamente socialista". Para Bandeira, a principal consequência do excesso de centralização é a burocratização.

Mas obviamente, a centralização política faz com que as decisões sejam monopolizadas pelo governo central, delegando a classe trabalhadora ao papel de implementadora das medidas tomadas hierarquicamente.

Para Bandeira (2002) "a falta de representatividade do sistema político cubano fica evidente" quando perguntamos se as candidaturas são livres:

\footnotetext{
Os candidatos têm liberdade e meios para se expressarem? As pessoas têm a possibilidade de se organizarem sem a tutela do PC e dos organismos de massa controlados por ele? Os poderes têm autonomia, e os organismos eleitos realmente tomam decisões ou são meros homologadores de ordens emanadas de outras instâncias? (Bandeira, 2002, p. 47).
}

Para Harnecker (1974), a falta de instituições realmente representativas dos interesses dos trabalhadores deveu-se à constante luta contra os dissidentes cubanos e o governo norte-americano. O que Harnecker não leva em conta é que não eram os trabalhadores que tinham a liderança predominante do processo, eles faziam parte da direção, mas a classe que decidiu os rumos a serem tomados foi, em grande parte, a pequena burguesia. O que não quer dizer que esta seja uma revolução burguesa, visto que muitos dos interesses atendidos eram do proletariado, o "timoneiro" da revolução foi uma pequena-burguesia nacionalista e radical.

Porém, como afirma Harnecker, a revolução em primeiro lugar, apoia-se em todo povo; em segundo lugar, possibilita a participação do povo como este jamais o teve em nenhuma outra sociedade humana; em terceiro lugar, existe uma incessante 
discussão e participação do povo em todas as medidas essenciais. As leis aqui discutem-se com o povo (Harnecker, 1974, p. 34). O que não quer dizer que sejam as classes populares o agente político decisivo.

Com a crise dos anos noventas, foram tomadas uma série de políticas governamentais que aumentaram as desigualdades sociais, como a abertura da economia cubana para o turismo, afetando diretamente as condições de vida dos trabalhadores.

\section{O Estado cubano e os trabalhadores}

Uma necessidade da revolução ressaltada por Fernandes (2007, p.267) se mantém até os dias de hoje, que é a de transformar o apoio e "consenso dos trabalhadores" em "participação política efetiva". O processo, que Fernandes ressalta, de "cefalização" (2007, p. 273) dos operários pelo partido funciona como cooptação, mantendo os mesmos dirigentes no poder e selecionando aqueles que mais se encaixam no funcionamento da máquina estatal. No Estado socialista são os trabalhadores que definem as diretrizes do seu Estado. Se o Estado realmente fosse dos trabalhadores não seriam necessários sindicatos para representá-los. Então como se dá à relação entre o Estado cubano e os trabalhadores?

Após o regime cubano aderir ao "socialismo" em 1961, foi implementada a lei de organização sindical que modificou toda a estrutura do movimento operário. Segundo Bandeira (2002, p. 298), essa lei "acabou com o pluralismo sindical e fixou como objetivo principal das organizações dos trabalhadores o cumprimento dos planos de produção do governo". Os sindicatos foram vinculados ao Estado, tornando-se parte dele, o que poderia ser algo benéfico, em razão da incorporação orgânica dos trabalhadores ao Estado Revolucionário.

Mas se a exploração do trabalho foi mantida, e esse Estado não era dos trabalhadores, era necessário que houvesse um organismo que representasse os trabalhadores nas suas relações de produção. Mas os sindicatos se tornaram "órgãos auxiliares da administração do Estado. Ao participarem de forma minoritária e acessória dos organismos de decisão, influem muito pouco e acabam estando para 
serem mais bem controlados pela elite política dirigente, e não para exercerem qualquer fiscalização ou pressão sobre ela" (Bandeira, 2002, p. 300). Para Córdova: “A classe trabalhadora e os sindicatos não participam do exercício do poder político, mas estão adscritos a ele" (apud Bandeira, 2002, p. 302). Segundo Bandeira, os sindicatos, em Cuba, parecem estar sempre atrelados à linha oficial, são representantes do Estado perante os trabalhadores, e não representantes dos trabalhadores perante o Estado. São instrumentos, "correias de transmissão" do Estado na sua relação com os trabalhadores. Para o autor, por meio "de eleições controladas os sindicatos elegem representantes 'recomendados' pelo partido, que têm como principal tarefa convencer os trabalhadores a executar a política do governo e a cumprir as metas de produção prescritas" (Bandeira, 2002, p. 318). Um caso em que se delineia o conflito de interesses entre o Estado Revolucionário e os trabalhadores é o do incentivo ao turismo em Cuba. Há um claro choque de interesses, visto que as medidas políticas tomadas, no que se refere ao turismo, introduziram latentes desigualdades sociais, medidas que beneficiaram um grupo em detrimento de outros. Importante para os trabalhadores era participar da implementação de tais medidas. O processo de decisão foi claramente tendencioso, representando os interesses de uma classe social já envolvida com o nascente capital turístico cubano, vinculado ao capital externo, em detrimento das classes populares.

Obviamente, aqueles que recebem em dólar se enriquecem relativamente mais que os envolvidos no setor econômico do peso cubano. Esse setor é composto principalmente pelos serviços estatais de saúde e educação. Como consequência, as condições de tais serviços enfrentam um sucateamento contínuo, e por conta disso esse setor opõe-se aos interesses dos trabalhadores em geral, os maiores beneficiados dos serviços públicos. A frágil, e até aparente, coesão social mantida até ali foi abalada com o enriquecimento de alguns setores da sociedade. Ao contrário do que defende Sader (2002, p. 111), o "destino" dos setores da sociedade não passou a ser decidido individualmente, mas pela mão forte do Estado:

É o governo quem determina, através de um órgão de distribuição de mão de obra, quem pode trabalhar na área do dólar. Apesar de o contrato ser feito em dólar, a agência do governo se apropria da moeda forte e paga ao empregado muito menos, e em moeda nacional, de acordo com a baixa escala salarial das empresas estatais cubanas (Bandeira, 2002, p.304). 
O incentivo ao turismo foi um meio de amenizar os efeitos perniciosos da crise econômica, mas a custo das condições sociais dos trabalhadores. Mesmo assim, as classes trabalhadoras foram preservadas em alguns aspectos:

A abertura ao capital estrangeiro permitiu investimentos em todos os ramos da economia, exceto em educação (não pode haver escola ou universidade privada em Cuba), saúde e no setor industrial-militar. Mas qualquer concessão ao capital estrangeiro na ilha obedece a umprazo determinado, de início e encerramento - um capitalismo a prazo fixo (Jinkings, 2004, p. 39).

Assim "na área do turismo, o governo intermedia a relação entre os trabalhadores e as empresas estrangeiras. As empresas pagam ao governo cubano em dólares que assalariam em pesos os trabalhadores". E a CTC (Central dos Trabalhadores Cubanos) não se coloca contra esse procedimento. "Tal processo acarreta na captação de uma gigantesca mais-valia pelo governo. (...) O dito Estado dos trabalhadores se instala como um imenso aparelho burocrático de exploração dos trabalhadores" (Córdova, 2002, p. 5).

Salientando estas implementações políticas contrárias aos interesses dos trabalhadores, confirmamos que a condução teórica e o comando efetivo da Revolução sempre estiveram nas mãos de uma minoria, encoberta pelo termo "vanguarda". (Bandeira, 2002, p. 305).

\section{Os níveis municipal, provincial e nacional}

Fernandes (2007, p. 277) vê nos anos 1970 a experiência derradeira do Poder Popular, interpretada como surgimento de um maior controle do Estado Revolucionário por parte dos trabalhadores. Hoje, levando em conta a experiência histórica, podemos dizer que este Poder Popular se manteve mais concentrado nos níveis locais e municipais, contrastando com a baixa presença do Poder Popular no nível nacional, fortemente hierarquizado.

Cada província tem sua Assembleia Provincial do Poder Popular. E cada município tem sua Assembleia Municipal do Poder Popular. São 14 províncias e 169 
municípios. Os eleitores de cada área, em reuniões públicas, nomeiam os candidatos a delegado às Assembleias Municipais. Nestas assembleias qualquer cidadão pode propor nomes.

O nível municipal pode ser caracterizado como o mais "popular" dos três níveis (municipal, provincial e nacional), justamente por configurar um maior espaço político para as reivindicações dos trabalhadores. É exercida sobre o nível municipal maior pressão popular, diferente do que acontece nos níveis provincial e nacional. As eleições municipais se dão a cada dois anos e meio. Aqueles que serão candidatos a delegado das assembleias municipais são selecionados em reuniões públicas, das quais qualquer cubano, com condições para votar, pode propor candidatos mediante voto aberto. Para Bandeira (2007, p. 48), esta é a primeira farsa no primeiro nível das eleições (municipais), 'pois apenas depois dessa fase de seleção é que começa a vigência do voto secreto.

Apesar dessa deficiência, as eleições em nível municipal trazem vários mecanismos de participação dos trabalhadores. O conjunto dos eleitores pode revogar o mandato dos delegados a qualquer momento quando não respondam aos seus interesses: "Mas os delegados não se limitam a este contato coletivo com seus eleitores: têm também um $<<$ dia de despacho $>$ por semana (...) que está destinado a atender às queixas, consultas e sugestões que individualmente lhe façam chegar os seus eleitores" (Harnecker, 1974, p. 220). Por isso, "é o delegado quem rende conta ante os eleitores e não o inverso. São as massas da circunscrição que têm o máximo poder, o primeiro poder; o poder do delegado é derivado, outorgado pelas massas" (Harnecker, 1974, p. 42). Aqui os trabalhadores realmente têm um forte papel de decisão:

Desta forma, visto que o Presidente, o Vice-presidente e o Secretário do Comitê Executivo Municipal se subordinam ao dito Comitê Executivo e à Assembleia Municipal; visto que o dito Comitê Executivo se subordina no seu conjunto a esta Assembleia e, por sua vez, visto que a dita Assembleia está integrada pelos delegados eleitos pelas massas e subordinadas às massas das suas respectivas circunscrições, o resultado de tal mecanismo é que são as massas que ostentam na prática o máximo poder e podem, por isso, ser na prática protagonistas ativos do processo com possibilidades concretas e institucionalizadas de decisão. (...) Foi também muito interessante a forma como foram eleitos os candidatos a delegados. Era a própria base que propunha e discutia se a pessoa proposta devia ser ou não eleito candidato, que condições tinha etc. (Harnecker, 1974, p. 43). 
São esses delegados de circunscrição que, além de ter o papel de constituir as Assembleias Municipais, lançam os candidatos para as Assembleias Provinciais e para a Assembleia Nacional.

Já o espaço de intervenção popular é menor nas Assembleias Provinciais do Poder Popular, já que se reúnem duas vezes ao ano e, enquanto estão de recesso, o Conselho de Estado - ou seja, o Comitê Executivo - controla seus políticos, já que o primeiro é nomeado pelo segundo. E os delegados das Assembleias Provinciais começaram a ser eleitos mediante voto secreto e direto recentemente. Até 1992, as eleições eram indiretas. A partir de outubro de 1992, as eleições passaram a ser diretas para deputados da Assembleia Nacional e para delegados das Assembleias Provinciais.

A constituição de Cuba reconhece o PCC como defensor primeiro do socialismo. Todos os órgãos de Estado são elegíveis e renováveis e podem ser revogados; a população controla as atividades de deputados, delegados e funcionários. A Assembleia Nacional do Poder Popular é o órgão supremo do sistema político cubano, tem poderes legislativo, administrativo e constituinte. Uma das funções da Assembleia Nacional do Poder Popular é exercer a mais alta fiscalização sobre os órgãos do Estado e do governo. Suas eleições são realizadas a cada cinco anos, com voto secreto e direto. Seus deputados se reúnem duas vezes ao ano, durante dez dias; enquanto isso o Conselho de Estado a representa governando por meio de decretos-lei.

A Assembleia Nacional elege o presidente do Conselho de Estado, que também engloba os cargos de presidente do Conselho de Ministros e do Conselho de Defesa Nacional. Posteriormente, ele propõe à Assembleia Nacional os nomes que comporão o Conselho de Ministros. Cada deputado deve reunir-se duas vezes ao ano com a população de sua comarca para prestação de contas podendo ser estes cargos revogados pela população. Mas os candidatos a ocupar o alto comissariado executivo e dos postos como o de Comandante-em-chefe, são eleitos pela Assembleia Nacional do Poder Popular, o que caracteriza uma eleição indireta. 
Essa configuração política traz consigo uma forte dose de hierarquização. 0 nível nacional entra em claro contraste frente o nível municipal, onde as medidas têm maior espaço para as decisões dos trabalhadores.

\section{Considerações finais}

Para Fernandes, o Estado socialista cubano deveria ser gerado pela "consistência adquirida pela compulsão igualitária da massa do povo e pela correspondente universalização da consciência revolucionária" (2007, p. 265), e não pelas mãos moldadoras do governo revolucionário. Mas, analisando os desdobramentos atuais, o que parece surgir da ação das massas cubanas não é o socialismo, pelo menos não foi exatamente o que se formou, mas uma alternativa amenizadora dos efeitos do neocolonialismo, da pobreza e do subdesenvolvimento.

Ao longo desse artigo vimos que não há o Estado socialista em Cuba, mesmo que vários aspectos de sua representação política se encaixem no socialismo por permitirem a autonomia e participação popular nos processos de decisão. Por isso podemos dizer que há em Cuba um Estado com caráter "nacional-popular". Tal Estado permite abrigar a manutenção do capitalismo junto à participação popular na formulação e implementação das medidas a serem tomadas. Dessa forma, atende a alguns dos interesses populares, mesmo mantendo uma classe dominante que predomina no controle do Estado.

No desenvolver de nossa argumentação, notamos que as ditas organizações de massas em Cuba são controladas organicamente pelo Partido Comunista, não representando os interesses dos trabalhadores devidamente, e sim atendendo a via oficial, reprodutora dos interesses de uma minoria ligada ao aparelho estatal.

Os trabalhadores não têm o controle efetivo do Estado em Cuba. Mas os trabalhadores interferem em parte dos processos de decisão política, exatamente por se tratar de um "Estado nacional-popular", que atende algumas das demandas do setor nacional e do proletariado em geral. Sendo assim, o excedente da produção captado pelo Estado cubano é revertido em sua maior parte para as necessidades da população. Assim não demos igualar a experiência cubana com as outras do Leste 
europeu, onde uma minoria se utilizou da exploração da mais-valia para enriquecimento próprio: “Existem diferenças sociais, sim, mas não se pode afirmar que em Cuba surgiu uma classe burguesa. O Estado continua bloqueando com firmeza as possibilidades de acumulação de capital privado e nenhum dos seus dirigentes enriqueceu ou foi corrompido" (JINKINGS, 2002, p. 39). Isso explica, em parte, porque o regime cubano resistiu à queda do bloco de países do Leste europeu.

Em Cuba, os trabalhadores não têm o papel predominante nos processos de decisão política, mas mesmo assim usufruem de alguns mecanismos políticos de autonomia que atendem a seus interesses:

\begin{abstract}
A saúde e a educação são gratuitas para todos; o analfabetismo foi erradicado, e todo o povo cubano a partir de 1985 goza de uma escolaridade mínima de nove anos de estudo (os seis anos foram conseguidos em 1980). O aluguel das casas não pode superar os $10 \%$ da renda dos seus moradores; o abastecimento de produtos básicos é garantido para todos: ninguém fica sem renda mínima. A prática de esportes é generalizada para toda a população e os espetáculos esportivos são gratuitos (Sader, 2001, p. 113).
\end{abstract}

As conquistas sociais são mundialmente conhecidas. Atingir os níveis sociais que Cuba atingiu é tarefa histórica realizada unicamente pelos cubanos no continente latino-americano. Diferentemente do que vemos no resto do continente latinoamericano, onde a democracia burguesa é vigente e as classes populares não têm meios políticos para fazer valer ao menos suas primeiras necessidades, as de educação, saúde e moradia. Se antes da revolução morriam em Cuba 78 crianças de cada mil, por causas evitáveis, e após a revolução morrem, atualmente, apenas 5,9 crianças de cada mil, foram evitadas - tendo como base a população atual que é de 12 milhões de pessoas - a morte de 795.920 pessoas. E em um país, como o Brasil, que tem uma população de quase 200 milhões de pessoas, onde ainda hoje a mortalidade infantil atinge 19,4 crianças de cada mil, quantas poderiam ter sido salvas?

\title{
Referências bibliográficas
}

Bambirra, Vânia. 1976. La Revolucion Cubana: uma reinterpretación. Cidade do México: Editorial Nuestro Tiempo. 
Banco Mundial. 2010. Indicadores do Desenvolvimento Mundial. Disponível em: http://www.google.com.br/publicdata/exploreds=d5bncppjof8f9_\&met_y=sh_dyn_mort\&idim

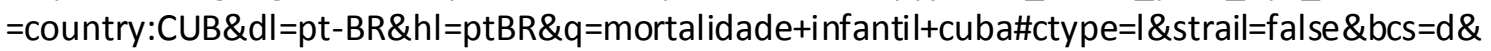
nsel $m=h \&$ met_y=sp_dy_le00_in\&scale_y=lin\&ind_y=false\&rdim=country\&idim=country:CUB: BRA:USA\&ifdi =country\&hl=pt_BR\&dl=pt_BR. Acessado em 25/01/2012.

Bandeira, Antônio Rangel. 2002. Sombras do Paraíso. Rio de Janeiro: Record, 2002.

Córdova, Efrén. 2000. La situación de los trabajadores en Cuba. ICCAS Serie de Monografías, Abril.

Cuba. 1992. Constitución de la Republica de Cuba de 1976. Havana: Editora Política.

Fernandes, Florestan. 1979. Da Guerrilha ao Socialismo: A Revolução Cubana. São Paulo: T. a Queiroz.

Fukuyama, Francis. 1992. O fim da história e o último homem. Rio de Janeiro: Rocco.

Harnecker, Marta. 1974. Cuba: Democracia ou Ditadura? São Paulo: Global.

Jinkings, Ivana. 2003. Uma contradição chamada Cuba. Margem Esquerda, São Paulo, número 2.

Sader, Emir. 2001. Cuba: Um Socialismo em Construção. Petrópolis: Vozes. 